ERP Indicators of Local and Global Text Influences on Word-to-Text Integration

Anne Helder ${ }^{1,2}$, Charles A. Perfetti ${ }^{1,3}$, Paul van den Broek ${ }^{2}$, Joseph Z. Stafura ${ }^{1,3}$, Regina C. Calloway $^{1}$

\footnotetext{
${ }^{1}$ Learning Research and Development Center, University of Pittsburgh, USA

${ }^{2}$ Institute of Education and Child Studies, Leiden University, the Netherlands

${ }^{3}$ Center for the Neural Basis of Cognition, Pittsburgh, PA
}

Corresponding author

Anne Helder helder@pitt.edu or Charles Perfetti perfetti@pitt.edu,

Learning Research and Development Center, University of Pittsburgh, USA

\title{
Acknowledgments
}

This research was supported by NIH award R01HD058566-02 to the University of Pittsburgh (Charles Perfetti, PI) and by the Netherlands Initiative Brain and Cognition (NIHC) to Leiden University (Paul van den Broek and Anne Helder) under grant number 056-33-010. The authors would like to thank Kimberly Muth and Emily Lustig for their help with stimulus creation and data collection. 
RUNNING HEAD: Local and Global Influences on WTI

Abstract

In two ERP experiments we examined local (recent text) and global (centrality) text influences on word-to-text integration. Participants read words that appeared across a sentence boundary or in text-final position. In both cases, the word was either related (central) or unrelated (noncentral) to the central theme of the passage. Additionally, words across a sentence boundary had an antecedent in the preceding sentence (local binding) or did not (baseline). Results indicate local-binding processes influence sentence-initial words with no additional effect of centrality, evidenced by a reduced N400 for central and non-central words with a local-binding opportunity relative to baseline. At text-final words, we observed a reduced P600 (Experiment 1) as well as an N400 (Experiment 2) for central relative to non-central words. This pattern suggests that integration across a sentence boundary is supported by local context and that over the course of continued reading, integration begins to reflect global text meaning.

Word count manuscript: 8097 (9439 including references) 


\section{ERP indicators of Local and Global Text Influences on Word-to-Text Integration}

The cognitive processes involved in reading comprehension take place at various levels: at the lexical level, where word meanings are accessed from word forms (e.g., Perfetti \& Hart, 2002), at the sentence level, where grammatical structures and their associated meanings are configured (e.g., Frazier \& Clifton, 1996; MacDonald, Pearlmutter, \& Seidenberg, 1994), and at the global, discourse level, as a mental representation of the text as a whole is constructed and updated (e.g., Graesser, Singer, \& Trabasso, 1994; Kintsch, 1988; van den Broek, 1994).

Factors at the global or discourse level influence how readers construct a mental representation of a text that is coherent and contains the meaning of the text, beyond its exact words. Evidence that readers attempt to maintain global coherence during reading comes from their ability to detect contradictions that are separated by several sentences (Albrecht \& O'Brien, 1993; O’Brien, Rizzella, Albrecht, \& Halleran, 1998) and to keep track of temporal, spatial, and causal information distributed across a narrative (Zwaan, Langston, \& Graesser, 1995). When probed after reading, readers show sensitivity to the causal structure of a text (Trabasso, Secco, \& van den Broek, 1984), to protagonists' goals and subgoals (van den Broek \& Trabasso, 1986), and to the information concerning the theme that is explicitly introduced at the beginning of the text (Lorch \& Lorch, 1985). Of special interest to the present study is the global text factor of centrality, or, more specifically, whether the central theme of a text influences the processing of incoming text information.

In considering how the global text factor of centrality exerts influence on comprehension, one question is whether its influence occurs as a specific word is read or whether it is distributed over the subsequent reading of a sentence or text. The aim of the current study is to examine this question. We first review the most relevant issues from discourse and word meaning research 
RUNNING HEAD: Local and Global Influences on WTI

that motivate our approach.

\section{The discourse level: coherent mental representation}

As readers progress through a text, they construct and update a mental model (JohnsonLaird, 1983) or situation model (Van Dijk \& Kintsch, 1983) of the text. This mental representation can be thought of as a conceptual network of text elements enriched by inferences made by the reader (e.g., Goldman \& Varma, 1995; Graesser \& Clark, 1985; Kintsch, 1988; O’Brien, Cook, \& Lorch, 2015; Trabasso \& van den Broek, 1985). In such a network, text elements differ in the degree to which they contribute to overall coherence, and, thus, to the degree that they are central to the semantic structure of the text.

Readers are sensitive to the structural centrality of text elements: They typically are more likely to retain central information from the text relative to information that is not central, retaining the gist rather than the details (for a review see van den Broek, Helder, \& Van Leijenhorst, 2013). For example, readers are more likely to recall parts of the texts that are highly connected to other parts of the text (e.g., Omanson, 1982; Thorndyke, 1977; Trabasso \& van den Broek, 1985); they include central elements more often in their summaries (e.g., Omanson, 1982; van den Broek \& Trabasso, 1986), and indicate them as more important (e.g., Brown \& Smiley, 1977; Omanson, 1982) than when text elements are not central to the semantic structure of the text.

Structural centrality has previously been investigated by asking participants to read relatively long stories (15-20 sentences) coded according to coarse units (e.g., clauses or sentences). However, most of these studies measure comprehension after reading, thus providing no information on the comprehension processes during reading. As a result, the potential influence of word processing on the mental representation of clauses, sentences, and discourse as 
a whole cannot be detected. Because comprehension proceeds incrementally, as readers integrate the meaning of each word with the evolving mental representation of the text (Boland, Tanenhaus, \& Garnsey, 1990; Tyler \& Marslen-Wilson, 1977), information on these integrative processes is important for theories of comprehension. Whether global-text factors, such as centrality, affect these integrative processes at the word level remains an open question.

\section{The Word Level: Multiple Integrative Processes}

The comprehension of words within a text proceeds along multiple levels. Consider for example the sentence 'The rain ruined her beautiful sweater'. To understand the word 'rain', several rapid, partly overlapping processes occur: identifying the word, retrieving its contextrelevant meaning, assigning its relational roles (syntactic/semantic) in the sentence and either integrating it into a current mental structure (proposition; mental model) or beginning a new structure (Gernsbacher, 1991; 1997; Perfetti, 1999). To examine such processes as they occur, event-related potentials (ERPs) are particularly useful, because they allow observations of multiple processes that overlap across a few hundred milliseconds of word reading. Perhaps most important for text comprehension, ERPs allow multiple opportunities to capture semantic binding processes that link word meanings to text meanings. Two ERP components, in particular, give indicators of how words are processed within their context. First, the N400, which generally reflects meaning congruence, provides a window on lexical-semantic processes that connect a word with the preceding context (e.g., Hagoort, Hald, Bastiaansen, \& Petersson, 2004; Kutas \& Federmeier, 2011; Kutas \& Hillyard, 1980; Van Petten, 1993; Yang, Pefetti, \& Schmalhofer, 2007). Second is the slightly later P600 or Late Positivity Component (LPC), although there is not a strong consensus on its functional interpretation (e.g., Brouwer, Fitz, \& Hoeks, 2012; Kuperberg, 2007; Van Petten \& Luka, 2012). However, in syntactically 
unambiguous situations the P600 can be taken to reflect memory operations, such as those related to recognition memory (old/new effect; Rugg \& Curran, 2007) or, in comprehension studies, to the updating of mental representations of text (discourse updating; Burkhardt, 2007; Schumacher \& Hung, 2012).

Global text factors have been shown to affect how words are processed in their context (e.g., Ferretti, Singer, \& Patterson, 2008; Kuperberg, Paczynski, \& Ditman, 2011; Nieuwland \& van Berkum, 2006; StGeorge, Mannes, \& Hoffman, 1994, 1997; van Berkum, Hagoort, \& Brown, 1999). For example, Nieuwland and Van Berkum (2006) found an N400 effect on locally plausible words (e.g., the peanut was salted) when these words did not fit in a global context that has introduced the peanut as an animate object about to fall in love. They found that, as a story unfolds, discourse context can neutralise (Experiment 1) or even overrule (Experiment 2) local lexical-semantic animacy violations. Although these studies assess global text effects on word processing in texts longer than two sentences, they focus on semantic anomalies, creating coherence breaks that disrupt normal reading. One way to examine word-level sensitivity to centrality during reading of coherent texts is the word-to-text integration (WTI) paradigm, which focuses on effects on reading words across a sentence boundary (Stafura \& Perfetti, 2014; Stafura, Rickles, \& Perfetti, 2015; Yang et al., 2007).

\section{Word-to-Text Integration Paradigm}

The WTI-paradigm has been used to examine how readers fit words into the mental representation of a short text (i.e., two sentences) by measuring electric scalp potentials (Electroencephalography; EEG) and segmenting ERPs in response to critical words. Important in the typical WTI study is that the word on which the ERP is measured is at the beginning of a sentence of a short text read passively. The reason for a focus on the sentence-initial position is 
that the first word across a sentence boundary is not an obligatory integration point. Words within sentences must be bound to within-sentence structures (clauses, noun phrases, verb phrases) and take on thematic or relational roles, influenced by powerful word prediction effects that typically emerge at the end of a sentence (e.g., Kutas \& Federmeier, 2011, Van Petten \& Kutas, 1990). The first word of a sentence has no within-sentence binding sites; instead it opens a new structure. In fact, beginning a new structure is the obligatory mental operation in reading the word across a sentence boundary and any integration with previous text information, either the preceding sentence or the text as a whole, is optional. Thus it is especially interesting to find that the first word of a sentence can prompt integration, as indicated by the N400 (Calloway \& Perfetti, 2017; Stafura \& Perfetti, 2014; Yang et al., 2007). For example, compare the following sentences in two conditions in which 'rain' is the critical word:

(1) While Cathy was riding her bike in the park, dark clouds began to gather, and it started to storm. The rain ruined her beautiful sweater.

(2) When Cathy saw there were no dark clouds in the sky, she took her bike for a ride in the park. The rain that was predicted never occurred.

In (1) the word 'rain' has a local binding opportunity in the preceding sentence; the word 'storm' serves as an antecedent to 'rain' and fine-tunes the mental representation evoked by the first sentence. In contrast, in (2) the word 'rain' has no antecedent in the preceding sentence so 'rain' is harder to integrate in (2) than (1). Results have shown an N400 effect: ERPs show a reduced negative amplitude around $400 \mathrm{~ms}$ after the onset of the critical word 'rain' in (1) relative to (2), indicating word-to-text integration processes referred to as a "paraphrase effect". Stafura \& Perfetti (2014) tested whether this effect is due only to lexical associations between 'storm' and 'rain', or whether it depended on the larger sentence context. In their text comprehension 
experiment, participants read sentence pairs in which the critical word (e.g., 'rain') had a local antecedent in the preceding sentence that was either strongly associated ('storm') or weakly associated ('shower'). In their meaning judgment experiment, these association strength differences produced clear N400 differences, with stronger associations producing a larger reduction in N400. However, in the text comprehension experiment, these strongly and weakly associated words produced equivalent reductions in the N400 relative to a baseline condition with no local antecedent. Thus, although lexical association strengths can produce N400 effects in text reading, the paraphrase effect also reflects factors at the message level. Thus, measuring word-to-text integration processes at words across a sentence boundary allows text factorslocal text binding and global text integration — to be studied.

Whereas previous WTI-studies have focused on words across a sentence boundary, words at sentence-final positions allow us to examine whether possible global text effects are distributed over the continued reading of a sentence. Words at sentence-final positions are more constrained by binding opportunities within a sentence (clauses, noun phrases) and are likely to elicit predictive processes (Kutas \& Federmeier, 2011; Van Petten \& Luka, 2012) and increased integrative processes (Just \& Carpenter, 1980; Rayner, Kambe, \& Duffy, 2000; Warren, White, \& Reichle, 2009) relative to words at sentence-initial positions. Accordingly, we examine here ERPs at both sentence beginnings and sentence endings.

\section{The Current Study}

Given the evidence for local binding across a sentence boundary, is the local level the only source of integration? Or can the more remote global properties of a text, instantiated here by centrality, also influence integration?

Our strategy is to manipulate two sources of information that are available to the reader 
during reading of a critical word across a sentence boundary: 1) a local binding opportunity at the end of the preceding sentence (i.e., an antecedent that is semantically related to the critical word) 2) the global text factor of centrality (i.e., a central theme that is either related or unrelated to the critical word). This allows a test of the relative influence of the local text context and the central theme of the text that is free of within-sentence structure building processes. In addition, to examine whether possible global text effects are distributed over the continued reading of a sentence, we also examine the influence of the global text factor of centrality on word-to-text integration processes at words at the end of a sentence.

In two experiments we adapted the WTI-paradigm by providing a central theme to previously used materials (Stafura \& Perfetti, 2014). In Experiment 1 we provided a threesentence context that sets up a central theme prior to the sentence that included the critical word to be measured. In Experiment 2 we boosted the global text factor of centrality even further by including a title capturing the central theme of the passage.

If the local context, i.e., the most recent proposition, is the only source of integration for words at the beginning of a sentence, we expect 1) a reduced N400 for words that have a local binding opportunity relative to a baseline with no such opportunity and 2) no differences in the N400 time window between words that are related to a central theme and words that are not. If, however, the global text factor of centrality has an additional effect on local binding processes that occur at words at the beginning of a sentence, we expect a reduced N400 for words that are related to the central theme relative to words that are not. There is a possibility that effects of centrality do not appear in the N400 time window, but do appear later as a P600 (Burkhardt, 2007; Schumacher \& Hung, 2012). Finally, if centrality has an effect on word-to-text integration processes over the continued reading of a sentence, we expect a reduced N400 or P600 at text- 
RUNNING HEAD: Local and Global Influences on WTI

final words that are related to the central theme relative to when they are not.

\section{Experiment 1}

\section{Method}

Participants. Forty-two undergraduate students of the University of Pittsburgh participated in this study. All were native English speakers with normal or corrected-to-normal vision and were right handed with no history of head injuries, neurological disorders or learning disabilities. The data of five participants were lost because of technical problems during data collection. After preprocessing the EEG data, the data of four participants were discarded because of artefacts such as excessive blinking, eye movements, and faulty electrodes. Thus, data from 33 participants (23 female, $M_{\text {age }}=18.82 ; S D=1.57$ ) were available for ERP analyses. All procedures were approved by the University of Pittsburgh's Institutional Review Board. All participants received course credits for their participation in the experiment.

Materials. Each participant read 90 four-sentence passages in a WTI paradigm (Stafura \& Perfetti, 2014; Yang et al., 2007). Centrality was manipulated by creating a central theme in the passages by explicitly referring to the central theme twice and by including three words within the first three sentences that were semantically related to the central theme. The fourth and final sentence is the sentence for ERP measurement. See Table 1 for an example. All passages are provided in the online supplementary materials.

The same critical word appeared at the beginning of the final sentence of each of the conditions for a given passage, which varied according to the opportunity it presented for integration of the critical word: (1) local binding + central condition (LB+C). The critical word had a local binding opportunity in the preceding sentence and was related to the central theme of the passage; e.g. the critical word 'rain' had a local antecedent in the preceding sentence 
('storm') and is related to the central theme 'weather'. (2) local binding + non central condition $(\mathrm{LB}+\mathrm{NC})$. The critical word had a local binding opportunity in the preceding sentence, but was unrelated to the central theme of the passage; e.g. the critical word 'rain' had a local antecedent in the preceding sentence ('storm'), but occurs in a passage with 'clothes' as the central theme. (3) Baseline condition. The critical word 'rain' has no local antecedent and occurs in a passage that is equal in length to the $\mathrm{LB}+\mathrm{C}$ and $\mathrm{LB}+\mathrm{NC}$ conditions. For the $\mathrm{LB}+\mathrm{C}$ and $\mathrm{LB}+\mathrm{NC}$ conditions, the fourth and final sentence was identical, including the text-final word; depending on condition, the text-final word was either central (C) or non central (NC). See Table 2 for Latent Semantic Analyses (LSA) values for a) critical words across a sentence boundary and the last five words of the preceding sentence (local context), b) critical words across a sentence boundary and the passage context; i.e. all words before the critical word (global context), and c) text-final words and the passage context. LSA values are consistent with our local and global context manipulation.

Three separate lists of 30 texts per condition were created and participants were randomly assigned to one of the three lists.

Critical word across a sentence boundary. The first critical word ('rain') appeared at the beginning of the final sentence where ERP's are measured and compared across three conditions: 1) $\mathrm{LB}+\mathrm{C}$ ('weather'), 2) LB+NC ('clothes') and 3) Baseline.

Text-final word. The second critical word ('sweater') appeared at the end of the final sentence. For text-final words the centrality effect is defined by a comparison of two conditions. 1) C ('clothes') and 2) NC ('weather'). (There is no baseline condition for the final word, so only an effect of Centrality beyond local binding is tested.) 
RUNNING HEAD: Local and Global Influences on WTI

(Table 1 about here)

(Table 2 about here)

Manipulation check. Before collecting ERP data, volunteers using Amazon's mechanical Turk (https://www.mturk.com/) rated the passages with a central theme to validate the centrality manipulation. Sixty-two native English speaking participants with an age range of 18-30 read each of the 90 four-sentence passages in their central or non-central condition (relative to critical words across a sentence boundary). They were instructed to indicate whether the passage was more about one or the other central theme on a 7-point Likert scale. For example, for the texts shown in Table 1, the scale was anchored by 'weather' on one end and 'clothes' on the other end of the scale. Passages were presented in one of two lists in a Qualtrics survey (http://www.qualtrics.com/) and counterbalanced across participants such that participants saw each passage only in one of the two conditions (with either weather or clothes as the central theme). Passages with a score 3, 4, or 5 were modified to make the central theme stronger. This was the case for five passages (of 180 total).

Procedure. Participants were fitted with an EEG net and seated inside a soundproof, electrically insulated booth on an adjustable chair $60 \mathrm{~cm}$ from the center of a $15-$ in. $(38.1 \mathrm{~cm})$ CRT display. They were instructed to read text passages for comprehension and to make true/false judgements to statements that followed each passage. All materials were presented in white letters on a black background, font Arial size 16, using E-prime (Version 2.0; Psychology Software Tools, Inc. Pittsburgh, PA, USA). Each trial began with a fixation cross displayed for $350 \mathrm{~ms}$. The first two sentences were then displayed as full sentences; after reading the first sentence, the participant pressed the spacebar to replace it with the second sentence. The third 
RUNNING HEAD: Local and Global Influences on WTI

and fourth sentences were presented one word at the time with an inter-stimulus interval (ISI) of $300 \mathrm{~ms}$ and a stimulus onset asynchrony (SOA) of $600 \mathrm{~ms}$. True/false statements were designed to be easy to answer when the reader attended to the content of the passage. Immediate feedback was given after each trial, either by "good job" for correct responses or "wrong" for incorrect responses.

The passages were presented in three blocks of 30 randomly ordered passages with short breaks between blocks. To ensure participants understood the task instructions, three practice trials preceded the experimental trials. The experiment took around 60 minutes to complete.

ERP recordings and preprocessing. All preprocessing steps were the same for critical words across a sentence boundary and text-final words. ERP recordings were made from a 128 electrode Geodesic sensor net (Tucker, 1993) with Ag/AgCl electrodes (Electrical Geodesics, Inc., Eugene, OR). During recording, all impedances were kept below $40 \mathrm{k} \Omega$ (Ferree, Luu, Russell, \& Tucker, 2001). A vertex reference was used during the recording. The EEG signals were digitally sampled at a rate of $1000 \mathrm{~Hz}$, and hardware filtered during recording between 0.1 and $200 \mathrm{~Hz}$.

A $30 \mathrm{~Hz}$ low-pass finite impulse response filter was applied to the recorded EEGs. EEGs were segmented from $200 \mathrm{~ms}$ before to $800 \mathrm{~ms}$ after the onset of the critical words $(1000 \mathrm{~ms}$ segments). Automatic artefact detection removed segments on the basis of blink detection on superior and inferior eye channels that showed voltage fluctuations of $>140 \mu \mathrm{V}$; horizontal eye movements (e.g., saccades) were detected at the left outer canthi electrode and removed for voltage fluctuations of $>55 \mu \mathrm{V}$. This procedure lead to the exclusion of $5.86 \%(S E=1.09 \%)$ of the trials for words across the sentence boundary and $4.09 \%(S E=0.83 \%)$ for text-final words. 
RUNNING HEAD: Local and Global Influences on WTI

This percentage was similar across conditions (all $p$ 's $>.162$ ). Finally, datasets were visually inspected for any remaining bad channels.

Following artefact rejection, removed channels were replaced by data from neighboring channels using spherical spline interpolation (Ferree, 2006). The data were then re-referenced to the average of the channels, as is common with dense-array electrode nets (Dien, 1998; Luck, 2005). The data were then averaged for each participant for each condition. A baseline correction was applied to the averaged waveforms by subtracting the mean amplitude of the baseline period (200 ms before critical words). The data were exported to SPSS 24.0 for statistical analyses.

\section{Results}

Behavioural data. Performance accuracy on the true/false statements that followed each passage was high, with an average of $92.8 \%(S D=0.04)$ across conditions.

ERP data. For measurements on the critical word across a sentence boundary and the text-final word, mean amplitudes between 300 and $500 \mathrm{~ms}$ (N400) and between 500 and $700 \mathrm{~ms}$ (P600) following word onset were averaged across participants. These time windows were based on previous ERP text research (e.g., Burkhardt, 2007; Calloway \& Perfetti, 2017; Stafura et al., 2015) and verified by visual inspection. Mean amplitudes for all participants were averaged over midline clusters $(\mathrm{Fz}, \mathrm{Cz}, \mathrm{Pz})$ and left and right central and parietal clusters $(\mathrm{C} 3, \mathrm{C} 4, \mathrm{P} 3, \mathrm{P} 4)$.

Figure 1 shows the electrodes used for each cluster. These midline, central, and parietal clusters cover a large region of the scalp where previous studies have found reliable N400 as well as P600 effects.

Local binding effects at critical words across a sentence boundary were tested by averaging mean amplitudes for $\mathrm{LB}+\mathrm{C}$ and $\mathrm{LB}+\mathrm{NC}$ and comparing them to Baseline in two 
RUNNING HEAD: Local and Global Influences on WTI

repeated measures ANOVAs: the first one was a 2 (Condition; LB vs Baseline) x 3 (Electrode cluster; Fz vs Cz vs Pz) ANOVA, referred to as the midline analysis. The second one was a 2 (Condition; LB vs Baseline) x 2(Cluster laterality; C3/P3 vs C4/P4) x 2(Cluster posteriority; $\mathrm{C} 3 / \mathrm{C} 4$ vs P3/P4) ANOVA, referred to as laterality analysis. To test additional global text influences beyond local binding, the same analyses compared mean amplitudes of $\mathrm{LB}+\mathrm{C}$ with LB+NC. The same analyses were applied to the mean amplitudes on the text-final words. Greenhouse-Geisser corrected $p$-values are reported when appropriate (i.e., when sphericity could not be assumed). Grand average waveforms for representative electrode clusters are displayed in Figure 2 for critical words across a sentence boundary and in Figure 3 for text-final words. Topographical maps and more ERP waveforms are provided as online supplementary files.

(Figure 1 about here)

\section{Critical word across a sentence boundary}

N400 analyses. The local binding opportunity produced an N400 effect, reflective of integration of words across a sentence boundary: words in the local binding conditions $(\mathrm{LB}+\mathrm{C}$ and $\mathrm{LB}+\mathrm{NC}$ ) elicited reduced negativity relative to words in the baseline condition. The global context of centrality had no additional effect: central $(\mathrm{LB}+\mathrm{C})$ and non-central $(\mathrm{LB}+\mathrm{NC})$ words did not differ reliably. These conclusions are based on the following analyses.

Midline analyses $(F z, C z, P z)$. The $\mathrm{N} 400$ was reduced for the local binding conditions $(\mathrm{LB}+\mathrm{C}$ and $\mathrm{LB}+\mathrm{NC})$ relative to Baseline; main effect of condition $F(1,32)=9.937, p=.004, \eta p^{2}$ $=.237$, that was qualified by an interaction of condition and electrode cluster, $F(2,64)=9.569, p$ $=.002, \eta \mathrm{p}^{2}=.230$; local binding conditions $(\mathrm{LB}+\mathrm{C}$ and $\mathrm{LB}+\mathrm{NC})$ showed reduced negativities relative to Baseline at both $\mathrm{Cz}\left(F(1,32)=13.184, p=.001, \eta \mathrm{p}^{2}=.292\right)$; and $\mathrm{Pz}(F(1,32)=$ 
RUNNING HEAD: Local and Global Influences on WTI

$\left.12.364, p=.001, \eta p^{2}=.279\right)$. There was no significant difference between condition at $\mathrm{Fz}(p=$ $.078)$ and was not in the expected direction $(\mathrm{LB}+\mathrm{C}$ and $\mathrm{LB}+\mathrm{NC}-$ Baseline $=-.440 \mu \mathrm{V})$.

There was no effect of centrality; $\mathrm{LB}+\mathrm{C}$ and $\mathrm{LB}+\mathrm{NC}$ did not differ significantly at midline clusters $(p=.261)$, nor was there an interaction of condition and electrode cluster $(p=$ .204) and their difference in means was not in the expected direction $(\mathrm{LB}+\mathrm{C}-\mathrm{LB}+\mathrm{NC}=-$ $.243 \mu \mathrm{V})$

Laterality analyses $(C 3, C 4, P 3, P 4)$. The N400 was reduced for the local binding conditions $(\mathrm{LB}+\mathrm{C}$ and $\mathrm{LB}+\mathrm{NC})$ relative to Baseline; main effect of condition $F(1,32)=15.306$, $p<.001, \eta p^{2}=.324$; local binding conditions showed reduced negativities relative to Baseline. There were no significant interactions related to condition (all p's $>.436$ ).

There was no effect of centrality; $\mathrm{LB}+\mathrm{C}$ and $\mathrm{LB}+\mathrm{NC}$ did not differ significantly $(p=$ $.159)$ and their difference in means was not in the expected direction $(\mathrm{LB}+\mathrm{C}-\mathrm{LB}+\mathrm{NC}=-$ $.227 \mu \mathrm{V})$. There were no interactions related to condition (all $p$ 's $>.196$ ).

Although combining the two local binding conditions for the first of two analyses followed the logic of our design, we also carried out a single ANOVA that separated local binding into central and non-central conditions followed by Bonferroni-corrected pairwise comparisons. Critical words in the $\mathrm{LB}+\mathrm{C}$ condition as well as in the $\mathrm{LB}+\mathrm{NC}$ condition showed reliable N400 reduction relative to words in the baseline condition in the same electrode clusters as reported in the result section (with the two local binding conditions collapsed). There were no differences between $\mathrm{LB}+\mathrm{C}$ and $\mathrm{LB}+\mathrm{NC}$.

P600 analyses. Although the local binding opportunity showed an effect in the P600 time window in $\mathrm{Cz}$ and $\mathrm{Pz}$ (only), this effect does not seem to be independent of the N400; nor is its frontal positivity what is expected for a discourse-related updating effect. This can be seen in the 
RUNNING HEAD: Local and Global Influences on WTI

topographical maps (see Supplementary materials). A late frontal positivity similar to what we observed is occasionally found in sentence processing, but is not interpreted as updating (Van Petten \& Luka, 2012). We did not find a difference between central (LB+C) vs. non-central $(\mathrm{LB}+\mathrm{NC})$ conditions in either the midline or laterality analyses.

\section{Text-final word}

N400 analyses. Centrality showed an effect of borderline reliability on text-final words in the N400 time window: Central (C) words elicited reduced negativity relative to non-central (NC) words in the N400 time window. These conclusions are based on the following analyses.

Midline analyses $(F z, C z, P z)$. The $\mathrm{N} 400$ was reduced for the $\mathrm{C}$ relative to $\mathrm{NC}$ condition, although marginally reliable: Main effect of condition, $F(1,32)=4.109, p=.051, \eta p^{2}=.114$, most visible at the $\mathrm{Cz}$ cluster. There was no significant interaction of condition by electrode cluster $(p=.603)$.

Laterality analyses (C3, C4, P3, P4). There were no N400 differences across conditions (all p’s >.172).

P600 analyses. Unlike for the word across the sentence boundary, centrality showed a clear effect on text-final words in the P600 time window: Non-central (NC) words elicited greater central and parietal positivities relative to central (C) words. The topographical maps (Supplementary materials) show the location of this effect and its separability from the N400. This centrality effect is based on the following analyses.

Midline analyses ( $F z, C z, P z)$. There were no P600 differences across conditions (all p's $>.135)$ 
RUNNING HEAD: Local and Global Influences on WTI

Laterality analyses $(C 3, C 4, P 3, P 4)$. The $\mathrm{P} 600$ was more positive for the $\mathrm{NC}$ than for the $\mathrm{C}$ condition: Main effect of condition, $F(1,32)=6.780, p=.014, \eta p^{2}=.175$. There were no significant interactions related to condition (all $p$ 's $>.131$ ).

(Figure 2 about here)

(Figure 3 about here)

\section{Discussion}

These results suggest that integration of words across a sentence boundary is largely driven by an early lexical-semantic binding process that connects the word to a local semantic representation established during reading of the previous sentence. This is evidenced by a reduced $\mathrm{N} 400$ for words that had a local binding opportunity ( $\mathrm{LB}+\mathrm{C}$ and $\mathrm{LB}+\mathrm{NC}$ conditions), i.e., an antecedent in the preceding sentence, relative to a baseline that had no local antecedent. ${ }^{1}$ The global text factor of centrality had no additional effect on word-to-text integration at the beginning of a sentence in either the N400 or P600 time windows. Across a sentence boundary, the local context (i.e., the most recent proposition) is more accessible in readers' mental

\footnotetext{
${ }^{1}$ Because the final word in the sentence that precedes the target sentence with the critical word differs between the baseline condition and the local binding conditions, we tested whether there were ERP differences between conditions on this final word. We tested all 6 clusters that showed a local binding effect $(\mathrm{C} 3, \mathrm{Cz}, \mathrm{C} 4, \mathrm{P} 3, \mathrm{Pz}, \mathrm{P} 4)$. There were no differences between conditions at any cluster ( $p$ s range from .297 to .954). Topographical maps and ERP waveforms are provided as online supplementary files.
} 
representation of texts than the global context (i.e., the central theme of the passage) — at least for the kinds of short texts in the current experiment.

By the final word of the sentence, word-to-text integration did include global text influences of centrality, mostly evidenced by a larger P600 for text-final words that were non central (NC) compared to central (C). Consistent with other ERP studies (Burkhardt, 2007; Schumacher \& Hung, 2012), we can take the P600 to reflect the ease of mental model updating. When words are related to the central theme of the passage, this updating occurs more easily than when they are not related to the central theme.

Although the results suggest that the global text factor of centrality does not affect integration processes at the beginning of a sentence, there is a question of the strength of our centrality manipulation. Three sentences preceding the critical word may not be sufficient to establish a central theme strong enough to produce an effect on sentence-initial words. One way to strengthen a central theme, while still keeping the texts short enough for ERP measures on large numbers of trials, is to begin each passage with a short title that captures its central theme.

\section{Experiment 2}

The goal of the second experiment was to stretch the boundary conditions for local and global binding effects on word-to-text integration by adding a title to the passages used in Experiment 1.

\section{Method}

Participants. Thirty-five participants were drawn from the same population of University of Pittsburgh undergraduate students as in the first experiment. All were again 
RUNNING HEAD: Local and Global Influences on WTI

English speakers, right-handed, with normal or corrected-to-normal vision and without a history of head injuries, neurological disorders or learning disabilities. The data of one participant were lost because of technical problems during the data collection. After preprocessing the EEG data, the data of four participants were discarded because of artefacts such as excessive blinking, eye movements, and faulty electrodes. Thus, data from 30 participants (13 female, $M_{\text {age }}=18.74 ; S D$ $=0.86)$ were available for ERP analyses. All procedures were approved by the University of Pittsburgh's Institutional Review Board. All participants received course credits for their participation in the experiment.

Materials and procedure. The materials consisted of the same 90 four-sentence passages as used in Experiment 1. However, to orient the readers toward the central theme of the passage, we provided a title to each of the passages in the experimental conditions. Titles consisted of the name of the protagonist and the central theme and were presented at the beginning of each passage in the $\mathrm{LB}+\mathrm{C}$ and $\mathrm{LB}+\mathrm{NC}$ conditions in a self-paced manner (see Table 2 for an example). Baseline passages did not contain a title.

(Table 3 about here)

\section{Results}

Behavioural data. Performance accuracy on the true/false statements that followed each passage was high, with an average of $93.9 \%(S D=0.04)$ across conditions.

ERP data. Data preprocessing and analyses were the same as in Experiment 1. For words across a sentence boundary, $7.52 \%(S E=1.33)$ of the trials were excluded and $7.39 \%(S E=$ 1.41) for text-final words. This percentage was similar across conditions (all $p$ 's $>.547$ ). Grand 
RUNNING HEAD: Local and Global Influences on WTI

average waveforms for representative electrode clusters are displayed in Figure 4 for critical words across a sentence boundary and in Figure 5 for text-final words. Topographical maps and more ERP waveforms are provided as online supplementary files.

\section{Critical word across a sentence boundary.}

N400 analyses. The local binding opportunity produced an N400 effect, reflective of integration of words across a sentence boundary: words in the local binding conditions $(\mathrm{LB}+\mathrm{C}$ and $\mathrm{LB}+\mathrm{NC}$ ) elicited reduced negativity relative to words in the baseline condition. The global context of centrality had no additional effect: central $(\mathrm{LB}+\mathrm{C})$ and non-central $(\mathrm{LB}+\mathrm{NC})$ words did not differ reliably. These conclusions are based on the following analyses.

Midline analyses $(F z, C z, P z)$. The N400 was reduced for the local binding conditions $(\mathrm{LB}+\mathrm{C}$ and $\mathrm{LB}+\mathrm{NC})$ relative to Baseline; the main effect was not significant $(p=.199)$, but there was an interaction of condition and electrode cluster, $F(2,58)=5.602, p=.014, \eta p^{2}=.162$; the local binding conditions ( $\mathrm{LB}+\mathrm{C}$ and $\mathrm{LB}+\mathrm{NC}$ ) showed reduced negativities relative to the baseline condition at the central parietal cluster $\left.(\mathrm{Pz}), F(1,29)=6.910, p=.014, \eta p^{2}=.192\right)$. There were no significant condition differences at Fz $(p=.075$, with means in unexpected direction $\mathrm{LB}+\mathrm{C}$ and $\mathrm{LB}+\mathrm{NC}-$ Baseline $=-.511 \mu \mathrm{V})$ or $\mathrm{Cz}(p=.400$, with means in expected direction $\mathrm{LB}+\mathrm{C}$ and $\mathrm{LB}+\mathrm{NC}-$ Baseline $=.177 \mu \mathrm{V})$.

There was no effect of centrality; $\mathrm{LB}+\mathrm{C}$ and $\mathrm{LB}+\mathrm{NC}$ did not differ significantly at midline clusters $(\mathrm{p}=.333)$, nor was there an interaction between condition and electrode cluster $(p=.786)$

Laterality analyses (C3, C4, P3, P4). The N400 was reduced for the local binding conditions ( $\mathrm{LB}+\mathrm{C}$ and $\mathrm{LB}+\mathrm{NC}$ ) relative to Baseline; main effect of condition, $F(1,29)=5.473, p$ $=.026, \eta p^{2}=.159$, that was qualified by an interaction of condition and cluster posteriority, $F(1$, 
$29)=8.111, p=.008, \eta p^{2}=.219$; local binding conditions $(\mathrm{LB}+\mathrm{C}$ and $\mathrm{LB}+\mathrm{NC})$ showed reduced negativities relative to Baseline at parietal clusters $(\mathrm{P} 3 / \mathrm{P} 4), F(1,29)=9.666, p=.004, \eta p^{2}=$ .250 , but not at central clusters $(\mathrm{C} 3 / \mathrm{C} 4), p=.489$.

There was no effect of centrality: $\mathrm{LB}+\mathrm{C}$ and $\mathrm{LB}+\mathrm{NC}$ did not differ significantly $(p=$ .860). The interaction of condition and cluster posteriority did not reach standard reliability, $F(1$, $29)=3.284, p=.080, \eta p^{2}=.102$. Follow-up analyses showed no effect of condition in any of the electrode clusters (all $p$ 's $>.301)$.

As for experiment 1, we did a single ANOVA including all three conditions. The results show a similar pattern of condition differences as reported in the results section, except that the local binding effect, with the local binding conditions collapsed, appears to be driven by the significant difference between Baseline and $\mathrm{LB}+\mathrm{NC}$; the difference between Baseline and $\mathrm{LB}+\mathrm{C}$ does not reach significance when corrected for multiple comparisons. There were no differences between $\mathrm{LB}+\mathrm{C}$ and $\mathrm{LB}+\mathrm{NC}$.

P600 analyses. As in Experiment 1, an apparent local binding effect (marginally significant) in the P600 time window was not independent of the N400. Also as in Experiment 1, the topographical maps (see Supplementary materials) showed a frontal late positivity. We did not find a difference between central $(\mathrm{LB}+\mathrm{C})$ vs. non-central $(\mathrm{LB}+\mathrm{NC})$ conditions in either the midline or laterality analyses.

We also examined the end of the preceding sentence for any ERP differences. As in Experiment 1, there were no significant differences between baseline and local binding conditions at any of the clusters that showed local binding effects on the target word. (See Footnote 1.) Here the clusters were $\mathrm{P} 3, \mathrm{Pz}$, and $\mathrm{P} 4$, with $p$ values ranging from .171 to .844. Topographical maps and ERP waveforms are provided as online supplementary files. 
RUNNING HEAD: Local and Global Influences on WTI

\section{Text-final word.}

N400 analyses. Centrality showed an effect on text-final words in the N400 time window: Central (C) words elicited reduced negativity relative to non-central (NC) words in the N400 time window. These conclusions are based on the following analyses.

Midline analyses $(F z, C z, P z)$. The $\mathrm{N} 400$ was reduced for the $\mathrm{C}$ relative to $\mathrm{NC}$ condition: Main effect of condition, $F(1,29)=4.212, p=.049, \eta \mathrm{p}^{2}=.127$. Condition interacted nonsignificantly with electrode cluster $(p=.092)$, with the centrality effect most apparent in the Pz cluster $(p=.024)$.

Laterality analyses (C3, C4, P3, P4). There were no N400 differences across conditions (all p’s > .191).

P600 analyses. As in Experiment 1, centrality showed an effect on text-final words in the P600 time window: Non-central (NC) words elicited greater positivities relative to central (C) words. This centrality effect is based on the following analyses. See supplementary materials for topographical maps.

Midline analyses. There were no P600 differences across conditions (all p's > .446).

Laterality analyses. The P600 was more positive for the $\mathrm{NC}$ than for the $\mathrm{C}$ condition: Main effect of condition, $F(1,29)=4.812, p=.036, \eta p^{2}=.142$. There were no significant interactions related to condition (all $p$ 's $>.776$ ).

(Figure 4 about here)

(Figure 5 about here)

\section{Discussion}


RUNNING HEAD: Local and Global Influences on WTI

The pattern of results was identical to those described in Experiment 1. However, when a title that captures the central theme of the passage was added, text-final words that were related to that central theme elicited not only reduced positivities in the P600 time window, but also reliably reduced negativities in the N400 time window, compared to words that were not related to the same words in the non-central theme texts. The title did not lead to cross-sentence boundary effects of centrality.

\section{General Discussion}

Our aim was to examine the influence of the global text factor of centrality on the integration of words into the reader's mental representation of a text. More specifically, for words across a sentence boundary we examined whether a local binding opportunity (i.e., a semantic antecedent at the end of the preceding sentence) is the only source of integration, or whether the more remote global properties of a text, in our case instantiated by centrality, also influence word-to-text integration.

The main findings of Experiment 1 indicate that word-to-text integration across a sentence boundary, as indexed by the N400, is largely driven by an early lexical-semantic process of binding the meaning of the word to the local context, in this case an antecedent at the end of the preceding sentence: A reduced N400 occurred for words with a local binding opportunity ( $\mathrm{LB}+\mathrm{C}$ and $\mathrm{LB}+\mathrm{NC}$ conditions) relative to a baseline that had no local antecedent, with no difference between the central $(\mathrm{LB}+\mathrm{C})$ and noncentral $(\mathrm{LB}+\mathrm{NC})$ conditions. Our interpretation is consistent with previous research with the WTI-paradigm (e.g., Stafura \& Perfetti, 2014; Yang et al, 2007). When a substantive word (e.g., a noun) begins a sentence (e.g., 'rain') with no local binding site in the preceding sentence (baseline condition), integration is blocked (a new structure is begun) and an N400 is observed. When a local binding site is 
available, a lexical-semantic process integrates semantic information across a sentence boundary. Thus when 'The rain' begins the sentence, integration can occur when 'started to storm' has appeared at the end of the prior sentence (see Table 1), producing a reduced N400. This description reflects the difference between baseline and the local binding conditions ( $\mathrm{LB}+\mathrm{C}$ and $\mathrm{LB}+\mathrm{NC}$ ). The global text factor of centrality had no additional effect on word-to-text integration at the beginning of a sentence. Furthermore, none of these effects for words across a sentence boundary changed when we boosted the global text factor of centrality by adding a title to the passages (Experiment 2).

To examine whether possible effects of centrality are distributed over the continued reading of a sentence, we also examined the influence of a central theme on word-to-text integration processes at words at the end of a sentence. In Experiment 1 we found evidence for global centrality influences at text-final words: greater positivities in the P600 time window when the word was not related to the central theme (NC) compared to when the word was related to the central theme (C). We take the P600 at the end of a sentence to reflect mental model updating (Burkhardt, 2007, Schumacher \& Hung, 2012). When words are related to the central theme of the passage, this updating occurs more easily compared to when they are not related to the central theme. When global text influence was increased by adding a title that captures the central theme of the passages, an additional N400 effect was observed at the sentence-final word, indicating a better semantic fit for words related to the central theme compared to when they are not.

Thus, within the limits of these short texts, the global text factor of centrality does not influence the processing of words across a sentence boundary; its effects are distributed over the continued reading of a sentence and/or text. Below, we offer a more detailed explanation for 
RUNNING HEAD: Local and Global Influences on WTI

sentence position influences in word-to-text-integration and discuss further global influences.

\section{Words across a sentence boundary.}

In written language, the first word of a sentence is special in forcing the reader to begin a new structure. Unlike later in the sentence, the first word has no binding sites within the sentence (such as clauses, noun phrases), except for the ones it will start to build. Thus, we suggest that integration — which, beyond within-sentence binding opportunities, refers to binding meanings and referents at the propositional and mental model levels - is not expected at the first word across a sentence boundary. Instead, the default process is to begin a new structure. One consequence for the reader is that words across a sentence boundary are relatively hard to predict. When integration does occur, the mechanism is memory-based integration more than word-based prediction (Calloway \& Perfetti, 2017). If building a new structure is the default, then integration must be triggered by highly accessible antecedent text information in memory. Such an antecedent is present for the 'The mail...' at the beginning of a sentence when it is preceded by '....to ship the letter.' (see Table 2). The binding of 'mail' to text memory can be based on lexical association (mail-letter), propositional integration (the meaning of 'mail' integrated with [Ship [letter]) and the finetuning of a mental model ('mail' added as an event to a model that includes a richer representation of going to the post office to send a letter or sending a letter to apply for college). It is likely that all three levels are involved in many cases, perhaps distributed over a few ms of processing. Evidence that propositional or message meaning is involved beyond lexical association in word-to-text integration comes from Stafura \& Perfetti (2014).

In a related study on cross-sentence boundary effects, Schumacher \& Hung (2012) found a reduced N400 for given relative to inferred sentence-initial words. In one of their examples the 
second sentence started with 'The author' and was preceded by either 'Yesterday, a student interviewed an author at the train station.' (given condition) or 'Yesterday, a student bought a novel at the train station.' (inferred condition). There was no baseline condition in this study. They interpret this N400 reduction as discourse linking, observing that "sentence-initial position functions to 'open' a new discourse layer in working memory relative to which subsequent content is stored" (p. 307). This opening can be seen as the default operation at a sentence boundary, as we suggested above.

In summary, for the word across a sentence boundary, integration with prior text is not required and may happen only when triggered by strong semantic links with text memory. Local antecedents are highly accessible and provide such triggers. The topical centrality of the antecedents does not strengthen this trigger, at least within the boundary conditions of these experiments. Such a boundary condition may be the accessibility of an antecedent, which here was always local, i.e. at the end of the preceding sentence. When antecedents are more remote, perhaps centrality would enhance their accessibility.

\section{Text-final words}

Whereas words at the beginning of a sentence may prompt readers to either build a new structure or integrate it with the local context of the preceding sentence, words at the end of a sentence have within-sentence binding opportunities and, in fact, binding obligations to complete open structures (clauses, noun phrases). Longer reading times at sentence endings are usually interpreted to reflect increased integrative processing for words at the end of a sentence (Just \& Carpenter, 1980; Rayner et al., 2000) although additional factors are involved (Warren et al., 2009). We found that centrality has an influence on word-to text integration processes at the end of a sentence, reflected in a P600 effect (Experiment 1); When Experiment 2 boosted passage 
RUNNING HEAD: Local and Global Influences on WTI

centrality with a title, this P600 effect was replicated and a reliable N400 effect of centrality was added.

Notable is the fact that, in both experiments, this P600 effect occurred only on the text final word and not on the word across the sentence boundary. We suggest that the end of a sentence presents an occasion for closing multiple structures that contribute to mental model updating. Thus, in our texts, the final word is comprehended, the final noun phrase, the verb phrase, and entire sentence are closed. By contrast, at the beginning of the sentence, the main work is to open new structures rather than close them. Whether mental model updating occurs more readily with closing sentence structures than opening them awaits further testing. However, it is likely that linguistic phrase structures contribute to the meaning processes that update a reader's mental model.

Although there is no clear consensus on the underlying cognitive mechanisms indexed by the P600, our findings on text final words are more consistent with the mental model or discourse updating interpretation (e.g., Burkhardt, 2007; Schumacher \& Hung, 2012) than with the old/new interpretation from the recognition memory literature (e.g., Rugg \& Curran, 2007). In our case this means that the word 'university' is easier to integrate in the passage context when presented in the central passage about 'Heidi applies for college' compared to the noncentral passage about 'Heidi's post office visit' in the earlier time window (N400), as well as in the later time window (P600). Thus, in terms used by Schumacher and Hung (2012), we have evidence of centrality effects on both discourse linking (N400), and discourse updating (P600). Although a P600 can be obtained in the absence of an N400 (e.g., Brouwer et al., 2012; Burkhardt, 2007), and vice-versa, it is not clear how these two signatures of integration are linked, when they are observed together. They may reflect a recurring integration process that 
varies over a very brief time, perhaps reflecting different phases of integration or different linguistic levels of word meaning-discourse memory binding (e.g., word level, propositional level, or mental model level).

In summary, for text-final words, integration with prior text is more likely than for words across a sentence boundary and this integration is influenced by centrality. When a text-final word is related to the central theme it is more easily integrated as well as updated into the mental representation of the text compared to when it is not related to the central theme.

\section{Word-to-text integration in longer discourse contexts}

Although our results suggest that centrality does not readily influence word-to-text integration processes at words across a sentence boundary, we cannot claim this is generalizable to the processing of words in longer texts. It could be that the lexical-semantic binding processes across a sentence boundary, triggered by the local binding opportunity, provide strong cues that limit the detection of global influences. Alternatively, even with a title, the discourse provided is not sufficient to build a representation of the central theme that is sufficient to produce an effect on words across a sentence boundary. Longer texts may be required for a reader to distinguish between central vs non-central information, or in the broader context of structural centrality, between the gist and the details of a text. Longer texts would also allow the use of connectivity analyses that reflect causal networks or other higher-level text structures (Omanson, 1982; Trabasso \& van den Broek 1985; van den Broek et al., 2013).

To conclude, our studies demonstrate that both local and global text factors influence the integration of words into the mental representation of short passages, depending on a word's position in the sentence. When there is a local binding opportunity for words at the beginning of the sentence, the local level appears to be the dominant source of integration, provided there is a 
RUNNING HEAD: Local and Global Influences on WTI

local binding opportunity; the global text factor of centrality shows no additional effect.

However, centrality does influence the processing of words at text-final positions. This suggests that global text factors, instantiated here by centrality, have a more remote influence on word-totext integration processes and seem to be distributed over the continued reading of a text.

\section{References}

Albrecht, J. E., \& O’Brien, E. J. (1993). Updating a mental model: Maintaining both local and global coherence. Journal of Experimental Psychology: Learning, Memory, and Cognition, 19, 1061-1070.

Boland, J. E., Tanenhaus, M. K., \& Garnsey, S. M. (1990). Evidence for the immediate use of verb control information in sentence processing. Journal of Memory and Language, 29(4), 413-432.

Brouwer, H., Fitz, H., \& Hoeks, J. (2012). Getting real about semantic illusions: rethinking the functional role of the P600 in language comprehension. Brain Research, 1446, $127-143$.

Brown, A. L., \& Smiley, S. S. (1977). Rating the importance of structural units of prose passages: A problem of metacognitive development. Child Development, 48, 1-8.

Burkhardt, P. (2007). The P600 reflects cost of new information in discourse memory. Neuroreport, 18(17), 1851-1854.

Calloway, R. C., \& Perfetti, C. A. (2017). Integrative and predictive processes in text reading: 
RUNNING HEAD: Local and Global Influences on WTI

The N400 across a sentence boundary. Language, Cognition and Neuroscience, 1-16.

Dien J. (1998). Issues in the application of the average reference: Review, critiques, and recommendations. Behavioral Research Methods, 30, 34-43.

Ferree, T. C. (2006). Spherical splines and average referencing in scalp electroencephalography. Brain Topography, 19(1), 43-52.

Ferree, T. C., Luu, P., Russell, G. S., \& Tucker, D. M. (2001). Scalp electrode impedance, infection risk, and EEG data quality. Clinical Neurophysiology, 112(3), 536-544.

Ferretti, T. R., Singer, M., \& Patterson, C. (2008). Electrophysiological evidence for the timecourse of verifying text ideas. Cognition, 108(3), 881-888.

Frazier, L., \& Clifton, C. (1996). Construal. Cambridge, MA: MIT Press

Gernsbacher, M. A. (1991). Cognitive processes and mechanisms in language comprehension: The structure building framework. In G. H. Bower (Ed.), The psychology of learning and motivation (pp. 217-263). New York: Academic Press

Gernsbacher, M. A. (1997). Two decades of structure building. Discourse Processes, 23(3), 265-304.

Goldman, S. R., \& Varma, S. (1995). CAPping the construction-integration model of discourse comprehension. In C. A. Weaver, S. Mannes, \& C. R. Fletcher (Eds.), Discourse comprehension: Essays in honor of Walter Kintsch (pp. 337-358). Hillsdale, NJ: Lawrence Erlbaum.

Graesser, A. C., \& Clark, L. F. (1985). Structures and procedures of implicit knowledge. Norwood, NJ: Ablex

Graesser, A., Singer, M., \& Trabasso, T. (1994). Constructing inferences during narrative comprehension. Psychological Review, 101(3), 371-395. doi: 10.1037/0033- 
RUNNING HEAD: Local and Global Influences on WTI

295X.101.3.371

Hagoort, P., Hald, L., Bastiaansen, M., \& Petersson, K. M. (2004). Integration of word meaning and world knowledge in language comprehension. Science, 304(5669), 438441.

Johnson-Laird, P. N. (1983). Mental models. Cambridge, MA: Harvard University Press.

Just, M. A., \& Carpenter, P. A. (1980). A theory of reading: From eye fixations to comprehension. Psychological Review, 87(4), 329.

Kintsch, W. (1988). The role of knowledge in discourse comprehension: A constructionintegration model. Psychological Review, 95(2), 163-182. doi: 10.1037/0033295X.95.2.163

Kuperberg, G. R. (2007). Neural mechanisms of language comprehension: Challenges to syntax. Brain Research, 1146, 23-49.

Kuperberg, G. R., Paczynski, M., \& Ditman, T. (2011). Establishing causal coherence across sentences: An ERP study. Journal of Cognitive Neuroscience, 23(5), 1230-1246.

Kutas, M., \& Federmeier, K. D. (2011). Thirty years and counting: Finding meaning in the N400 component of the event related potential (ERP). Annual Review of Psychology, $62,621-647$.

Kutas, M., \& Hillyard, S. A. (1980). Reading senseless sentences: Brain potentials reflect semantic incongruity. Science, 207(4427), 203-205.

Lorch, R. F., \& Lorch, E. P. (1985). Theme structure representation and text recall. Journal of Educational Psychology, 77(2), 137-148.

Luck, S. J. (2005). An introduction to the event-related potential technique. Cambridge: MIT Press. 
RUNNING HEAD: Local and Global Influences on WTI

MacDonald, M. C., Pearlmutter, N. J., \& Seidenberg, M. S., (1994). The lexical nature of syntactic ambiguity resolution. Psychological Review, 101(4), 676-703.

Nieuwland, M. S., \& Van Berkum, J. J. (2006). When peanuts fall in love: N400 evidence for the power of discourse. Journal of Cognitive Neuroscience, 18(7), 1098-1111.

O’Brien, E. J., Cook, A. E., \& Lorch, R. F. (Eds). (2015). Inferences during reading. Cambridge UK: Cambridge University Press.

O’Brien, E. J., Rizzella, M. L., Albrecht, J. E., \& Halleran, J. G. (1998). Updating a situation model: A memory-based text processing view. Journal of Experimental Psychology: Learning, Memory, and Cognition, 24(5), 1200-1210.

Omanson, R. C. (1982). An analysis of narratives: Identifying central, supportive, and distracting content. Discourse Processes, 5(3-4), 195-224.

Perfetti, C. A. (1999). Comprehending written language: A blueprint of the reader. In C. Brown \& P. Hagoort (Eds.), The neurocognition of language (pp. 167-208). New York, NY: Oxford University Press.

Perfetti, C. A., \& Hart, L. (2002). The lexical quality hypothesis. In L. Verhoeven, C. Elbro \& P. Reitsma (Eds.), Precursors of Functional Literacy (pp. 189-213). Amsterdam: John Benjamins Publishing Company.

Rayner, K., Kambe, G., \& Duffy, S. A. (2000). The effect of clause wrap-up on eye movements during reading. The Quarterly Journal of Experimental Psychology: Section A, 53(4), 1061-1080.

Rugg, M. D., \& Curran, T. (2007). Event-related potentials and recognition memory. Trends in Cognitive Sciences, 11(6), 251-257.

Schumacher, P. B., \& Hung, Y. C. (2012). Positional influences on information packaging: 
RUNNING HEAD: Local and Global Influences on WTI

Insights from topological fields in German. Journal of Memory and Language, 67(2), 295-310.

Stafura, J. Z., \& Perfetti, C. A. (2014). Word-to-text integration: Message level and lexical level influences in ERPs. Neuropsychologia, 64, 41-53.

Stafura, J. Z., Rickles, B., \& Perfetti, C. A. (2015). Memory and predictive mechanisms in on-line text comprehension: Lexical association direction and word-to-text integration assessed with ERPs. Language, Cognition, and Neuroscience, 30(10), 1273-1290.

StGeorge, M., Mannes, S., \& Hoffman, J. E. (1994). Global semantic expectancy and language comprehension. Journal of Cognitive Neuroscience, 6(1), 70-83.

StGeorge, M., Mannes, S., \& Hoffman, J. E. (1997). Individual differences in inference generation: An ERP analysis. Journal of Cognitive Neuroscience, 9(6), 776-787.

Thorndyke, P. W. (1977). Cognitive structures in comprehension and memory of narrative discourse. Cognitive Psychology, 9(1), 77-110.

Trabasso, T., Secco, T., \& van den Broek, P. (1984). Causal cohesion and story coherence. In H. Mandl, N. L. Stein \& T. Trabasso (Eds.), Learning and comprehension of text (pp. 83-111). Hillsdale, NJ: Lawrence Erlbaum Associates.

Trabasso, T., \& van den Broek, P. W. (1985). Causal thinking and the representation of narrative events. Journal of Memory and Language, 24, 612-630.

Tucker, D. M. (1993). Spatial sampling of head electrical fields: The geodesic sensor net. Electroencephalography and Clinical Neurophysiology, 87(3), 154-163.

Tyler, L. K., \& Marslen-Wilson, W. D. (1977). The on-line effects of semantic context on syntactic processing. Journal of Verbal Learning and Verbal Behavior, 16(6), 683692. 
RUNNING HEAD: Local and Global Influences on WTI

Van Berkum, J. J., Hagoort, P., \& Brown, C. M. (1999). Semantic integration in sentences and discourse: Evidence from the N400. Journal of Cognitive Neuroscience, 11(6), $657-671$.

van den Broek, P. (1994). Comprehension and memory of narrative texts: Inferences and coherence. In M. A. Gernsbacher (Ed.), Handbook of Psycholinguistics (pp. 539-588): New York: Academic Press.

van den Broek, P. W., Helder, A., \& Van Leijenhorst, L. (2013). Sensitivity to Structural Centrality: Developmental and individual differences in reading comprehension skills. In M. A. Britt, S. R. Goldman \& J-F Rouet (Eds), Reading: From words to multiple texts (pp. 132-146). New York: Routledge, Taylor \& Francis.

van den Broek, P., \& Trabasso, T. (1986). Causal networks versus goal hierarchies in summarizing text. Discourse Processes, 9(1), 1-15.

Van Dijk, T. A. and Kintsch, W. (1983). Strategies of discourse comprehension, New York, NY: Academic Press.

Van Petten, C. (1993). A comparison of lexical and sentence-level context effects in eventrelated potentials. Language and Cognitive Processes, 8(4), 485-531.

Van Petten, C., \& Kutas, M. (1990). Interactions between sentence context and word frequency in event-related brain potentials. Memory \& Cognition, 18(4), 380-393.

Van Petten, C., \& Luka, B. J. (2012). Prediction during language comprehension: Benefits, costs, and ERP components. International Journal of Psychophysiology, 83(2), $176-$ 190.

Warren, T., White, S. J., \& Reichle, E. D. (2009). Investigating the causes of wrap-up effects: Evidence from eye movements and E-Z Reader. Cognition, 111(1), 132-137. 
RUNNING HEAD: Local and Global Influences on WTI

Yang, C. L., Perfetti, C. A., \& Schmalhofer, F. (2007). Event-related potential indicators of text integration across sentence boundaries. Journal of Experimental Psychology:

Learning, Memory, and Cognition, 33, 55-89.

Zwaan, R. A., Langston, M. C., \& Graesser, A. C. (1995). The construction of situation models in narrative comprehension: An event-indexing model. Psychological Science, 6, 292297. 
Table 1. Example Passage (Experiment 1)

\begin{tabular}{|l|l|}
\hline Central theme & $\begin{array}{l}\text { Cathy likes to check the weather all the time on her iPhone. } \\
\text { She is always very excited when stormy weather is predicted. } \\
\text { While Cathy was riding her bike in the park, dark clouds began to gather, and it started to storm. } \\
\text { The rain ruined her beautiful sweater. }\end{array}$ \\
True or False: Caty is interested in the weather. \\
\hline Clothes & $\begin{array}{l}\text { Cathy loves clothes and bought herself a new wardrobe. } \\
\text { She is getting ready to go outside and decides to wear her new outfit today. } \\
\text { She noticed that a lot of people were looking at her clothes while it started to storm. } \\
\text { The rain ruined her beautiful sweater. }\end{array}$ \\
True or False: Cathy recently bought new clothes.
\end{tabular}


RUNNING HEAD: Local and Global Influences on WTI

Table 2. Means (and SD) of LSA Cosine Values ${ }^{1}$ for Local and Global Context Manipulations for Critical Words Across a Sentence Boundary and Text-final Words.

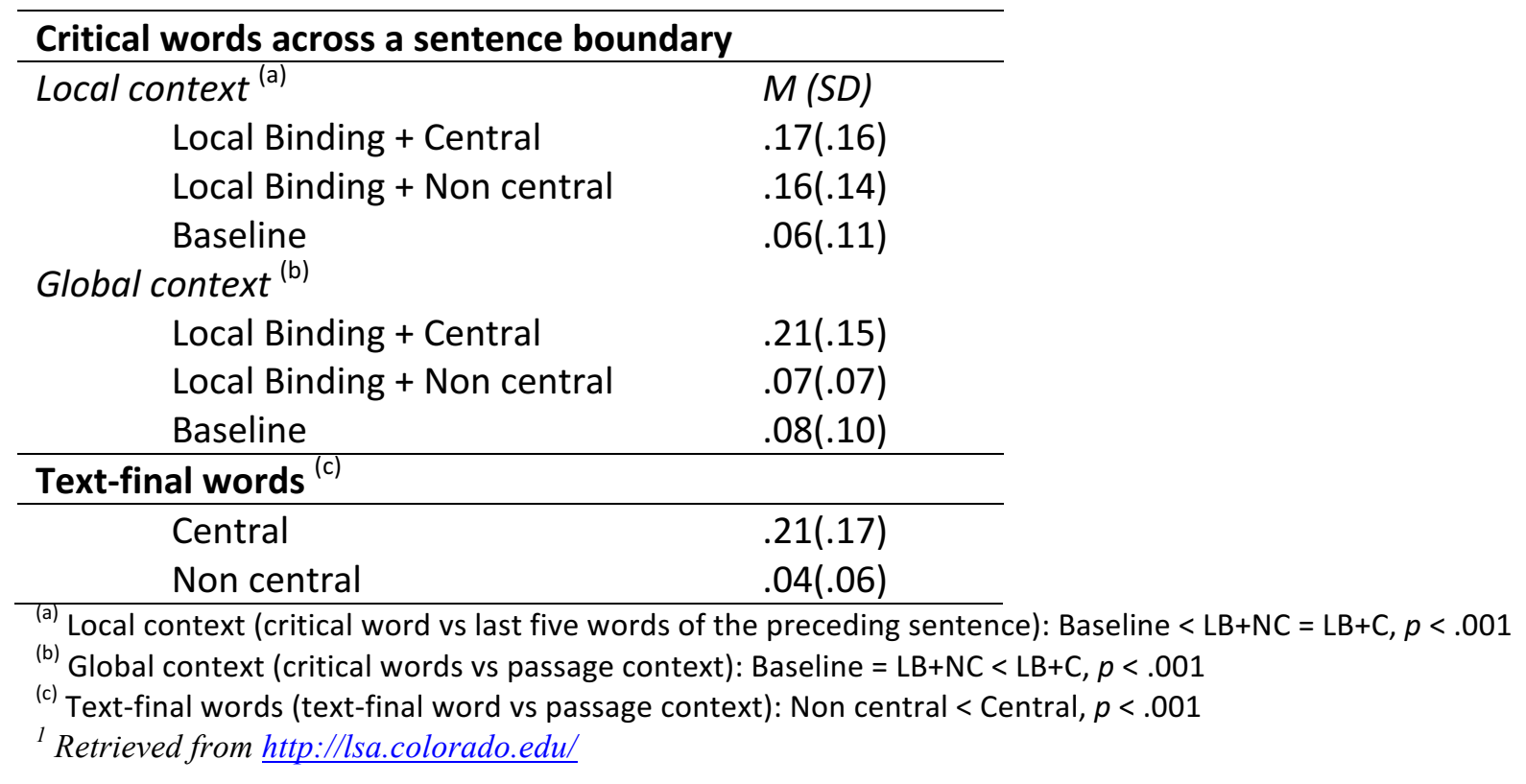


Table 3. Example Passage with Title (Experiment 2)

\begin{tabular}{|l|l|}
\hline Central theme & \begin{tabular}{l}
\multicolumn{1}{c}{ Heidi's Post Office Visit } \\
Heidi is on her way to the post office. \\
She still prefers writing letters over email because she thinks it is more personal. \\
After stamping the envelope, Heidi went to the post office to ship the letter. \\
The mail would take three days to get to the university. \\
True or False: Heidi is posting a letter.
\end{tabular} \\
\hline Central theme & $\begin{array}{l}\text { Heidi is applying for college and has finally decided which schools she wants to go. } \\
\text { She applied to her favorite schools and she had to write an essay. } \\
\text { She printed her application forms and was ready to ship the letter. } \\
\text { The mail would take three days to get to the university. }\end{array}$ \\
True or False: Heidi is applying for college.
\end{tabular}




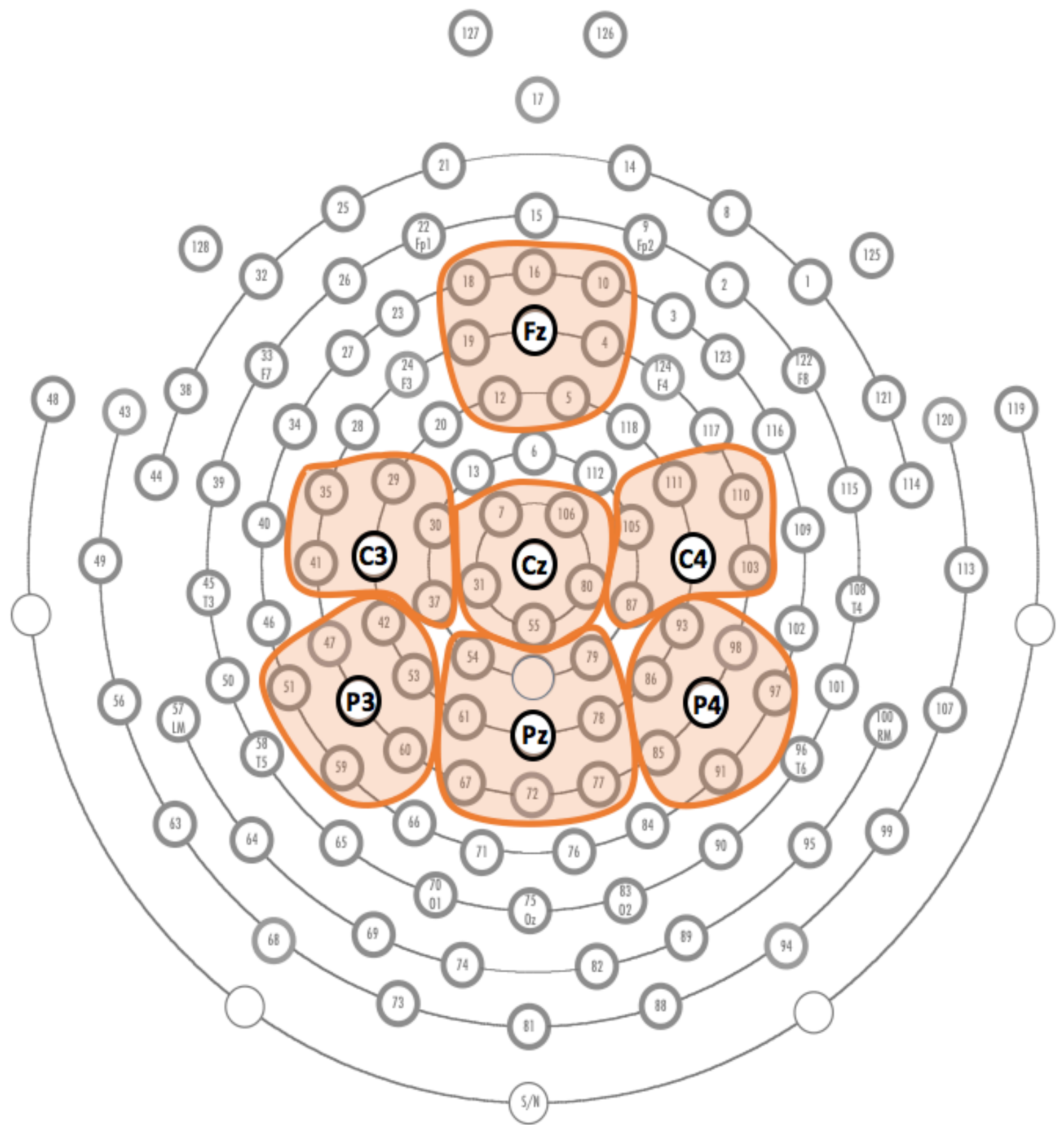

Figure 1. Electrode clusters used in the Midline analyses $(\mathrm{Fz}, \mathrm{Cz}, \mathrm{Pz})$ and Laterality analyses (C3, C4, P3, P4) for the 128 electrode HydroCel Geodesic Sensor Net 1.0. 


\section{Experiment 1 \\ Critical words across a sentence boundary}

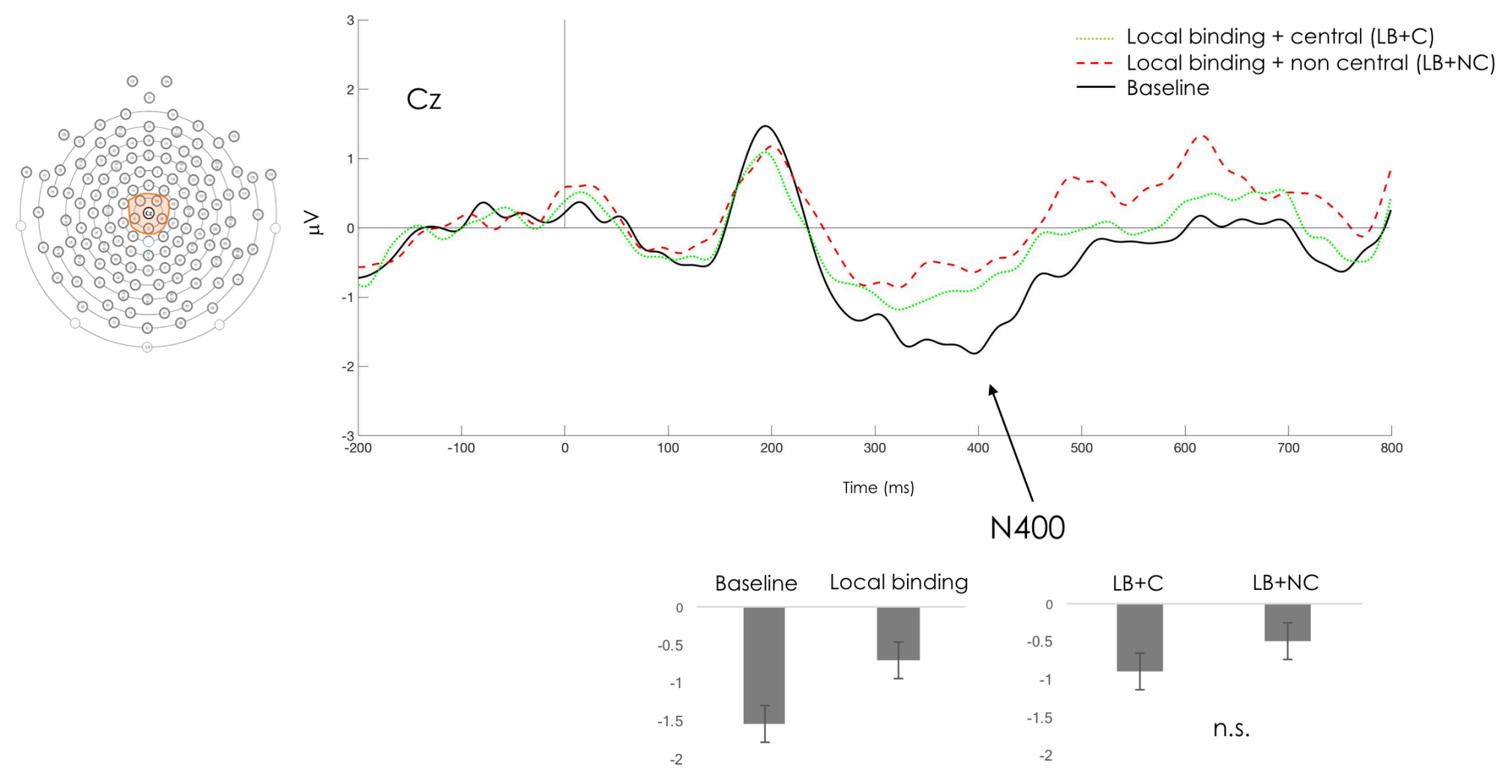

Figure 2. Grand average wave form for a representative electrode cluster $(\mathrm{Cz})$ for words in central (LB+C), non-central (LB+NC), and baseline condition. Negativity is plotted downwards. The bar graphs represent the average amplitudes in the N400 time window (300$500 \mathrm{~ms}$ ) for baseline and local binding $(\mathrm{LB}+\mathrm{C}$ and $\mathrm{LB}+\mathrm{NC})$ conditions (left) and central $(\mathrm{LB}+\mathrm{C})$ and non-central $(\mathrm{LB}+\mathrm{NC}) \mathrm{conditions}$ (right). 


\section{Experiment 1 Text-final words}
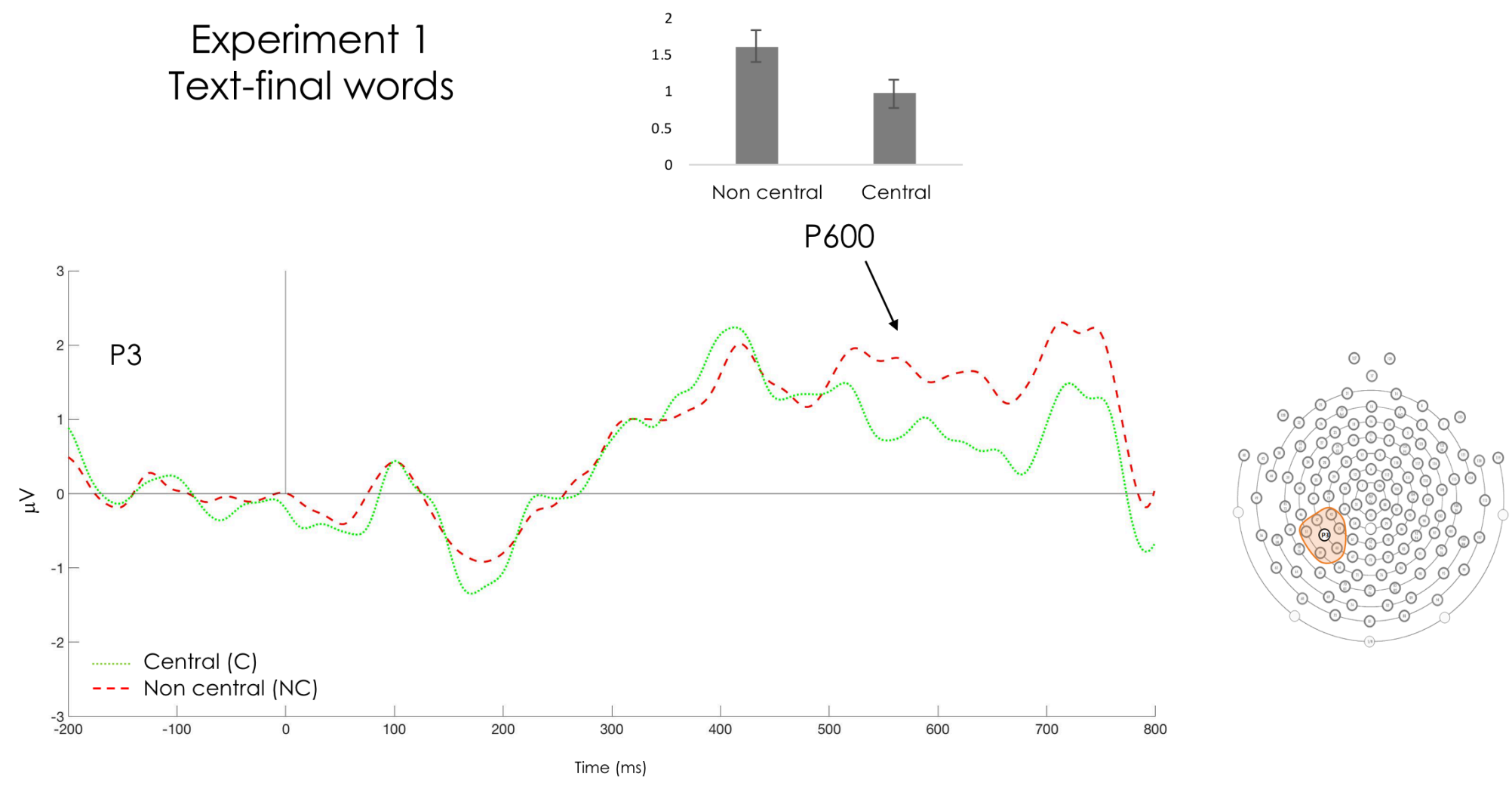

Figure 3. Grand average wave form for a representative electrode cluster (P3) for words in central (C) and non-central (NC) condition. Negativity is plotted downwards. The bar graphs represent the average amplitudes in the P600 time window (500-700 ms) for each condition. 


\section{Experiment 2 \\ Critical words across a sentence boundary}
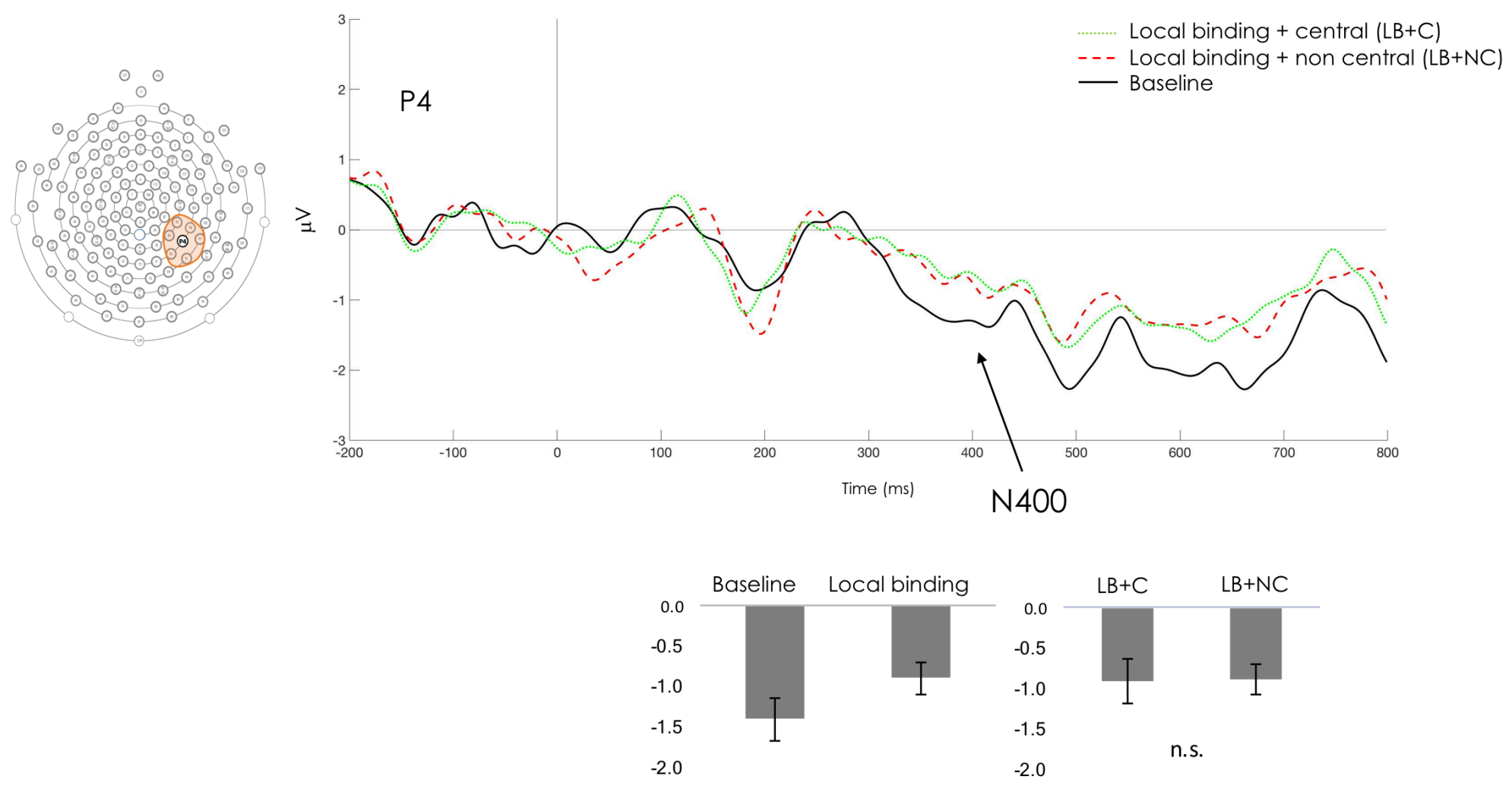

Figure 4. Grand average wave form for a representative electrode cluster (P4) for words in central (LB+C), non-central (LB+NC), and baseline condition. Negativity is plotted downwards. The bar graphs represent the average amplitudes in the N400 time window (300$500 \mathrm{~ms}$ ) for baseline and local binding $(\mathrm{LB}+\mathrm{C}$ and $\mathrm{LB}+\mathrm{NC})$ conditions (left) and central $(\mathrm{LB}+\mathrm{C})$ and non-central $(\mathrm{LB}+\mathrm{NC})$ conditions (right). 


\section{Experiment 2 Text-final words}

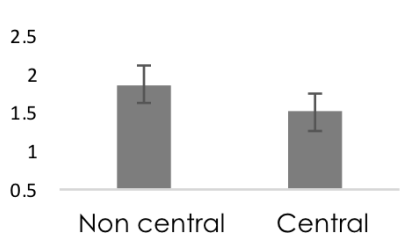

引

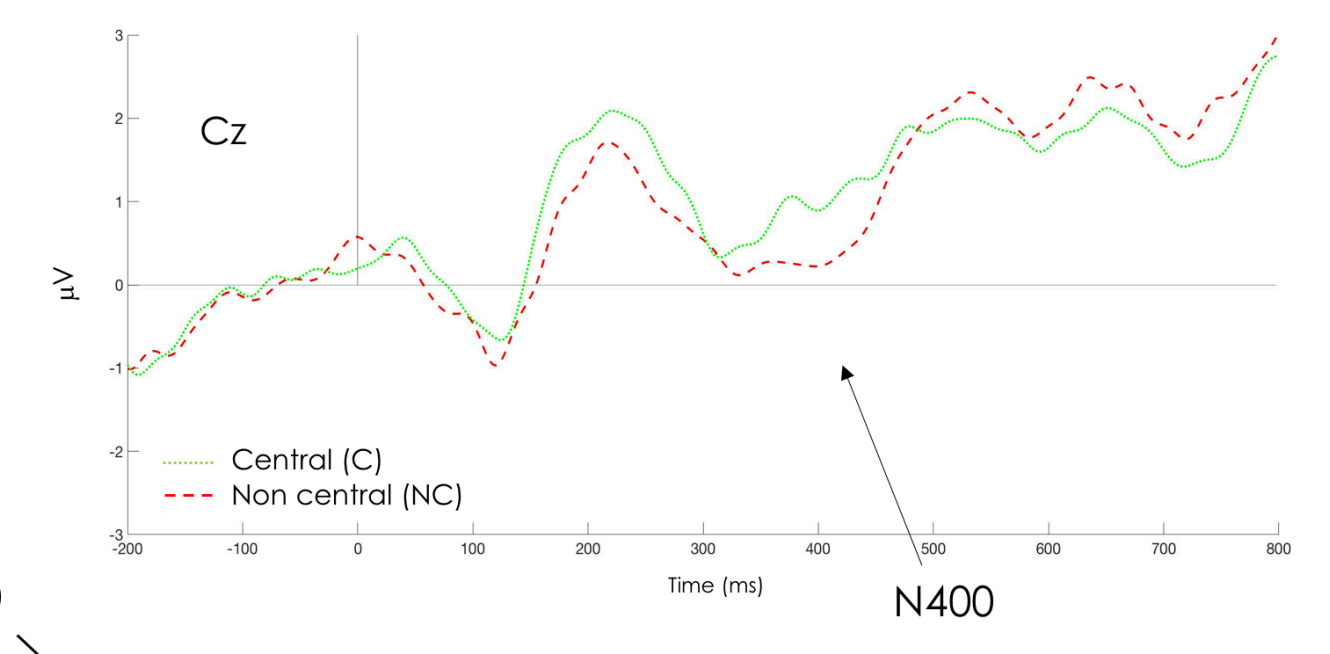

P600

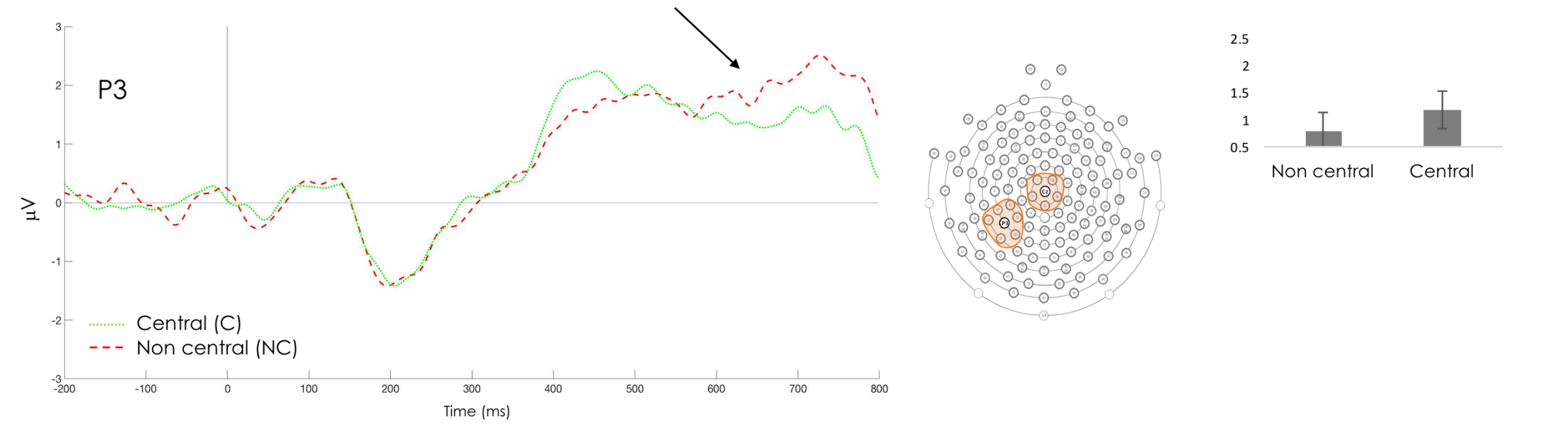

Figure 5. Grand average wave form for two representative electrode clusters ( $\mathrm{P} 3$ and $\mathrm{Cz}$ ) for words in central (C) and non-central (NC) condition. Negativity is plotted downwards. The bar graphs represent the average amplitudes in the N400 time window (300-500 $\mathrm{ms})$ and the P600 time window (500-700 ms) for each condition. 